\title{
MICROSTRUCTURE CONTROL OF Ni BASE ALLOYS WITH HIGH VOLUME FRACTION OF $D_{22}$ COMPOUND
}

\author{
Akane Suzuki $^{1}$, Takashi Matsuo ${ }^{2}$, Masao Takeyama ${ }^{2}$ \\ ${ }^{1}$ University of Michigan; 3062 H.H. Dow, 2300 Hayward St., Ann Arbor, MI 48109, USA \\ ${ }^{2}$ Tokyo Institute of Technology; 2-12-1 Ookayama, Meguro-ku, Tokyo 152-8552, Japan
}

Keywords: $\mathrm{Ni}_{3} \mathrm{~V}, \mathrm{D}_{22}$, misfit strain, coherent morphology, habit plane

\begin{abstract}
Formation and morphology of $\mathrm{A} 1 / \mathrm{D}_{22}$ two-phase microstructure have been investigated in $\mathrm{Ni}-\mathrm{V}$ alloys in order to study the fundamentals for microstructure control of wrought alloys containing high volume fraction of tetragonal compound. In the hypo-stoichiometric composition of $\mathrm{Ni}_{3} \mathrm{~V}$, formation of "multivariant structure (MVS)" consisting of $\mathrm{D}_{22}$ single phase takes place below $\mathrm{T}_{0}$ temperature. By aging in the $\mathrm{A} 1 / \mathrm{D}_{22}$ two-phase region, A1 phase is introduced into MVS via two different modes: precipitation with incoherent interfaces and continuous phase separation with coherent interfaces. The latter case is attractive because the interface between the two phases remains coherency after long-term aging at elevated temperatures, even though coarsening of $\mathrm{DO}_{22}$ phase occurs. In the binary alloy, the morphology of coherent two-phase microstructure becomes "maze", where the $\mathrm{D}_{22}$ phase has plate in shape with irrational

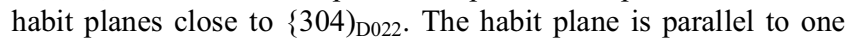
of the $a$-axes of $\mathrm{D}_{22}$ and an invariant line between the two phases, since the misfit strains along $a$ - and $c$-axes of $\mathrm{D}_{22}, \delta_{a}$ and $\delta_{c}$, respectively, have the relationship of $\delta_{a}<0<\delta_{c}$. The calculation based on the lattice invariant theory as well as experimental results clearly demonstrate that the misfit strain ratio $\delta_{c} / \delta_{a}$ is a dominant factor to determine the habit plane and that the value of $\left|\delta_{a}\right|$ is the key factor for the shape of $\mathrm{D}_{22}$ phase. The reduction in $\left|\delta_{a}\right|$ can change the shape drastically from plate into prism elongated along an $a$-axis, leading to the formation of thermally stable "chessboard" microstructure in the two-phase alloys.
\end{abstract}

\section{Introduction}

The volume fraction of $\mathrm{Ni}_{3}(\mathrm{Al}, \mathrm{Ti})-\gamma^{\prime}\left(\mathrm{Ll}_{2}\right)$ phase is one of the most important factors for high temperature strength in Ni base superalloys. The single-crystal superalloys usually contain more than 70 vol. $\%$ of $\gamma^{\prime}$ phase by means of composition control and heat treatment. On the other hand, wrought Ni base alloys usually have the volume fraction less than $50 \%$, because wide window is required for the hot working process. In the case of Waspaloy, the volume fraction is known to be limited up to $50 \%$ at the most. However, the limitation can be overcome by using Kurnakov type compounds as strengtheners. This type of compounds has a congruent disordering temperature $\mathrm{T}_{\mathrm{C}}$, above which the wide range of process window exists. In addition, control of microstructure as well as the volume fraction (up to $100 \%$ ) can be possible through cooling process. Therefore, obtaining the fundamental knowledge for microstructure control using Kurnakov type compounds opens new possibility for developing new wrought Ni base alloys, especially for steam turbines of USC (ultra-super critical) power plants operated at over $700^{\circ} \mathrm{C}$. In this study, we select $\mathrm{Ni}_{3} \mathrm{~V}$ as a model case based on the following two reasons; one is the high $\mathrm{T}_{\mathrm{C}}(1318 \mathrm{~K})$ at its stoichiometric composition $[1,2]$, and the other is crystal structure of tetragonal $\mathrm{D}_{22}$. This structure has two misfit strains against fcc (A1) matrix along $a$ - and $c$-axes, while $\gamma^{\prime}$ phase has only one. It is known that $\mathrm{Ni}_{3} \mathrm{~V}$ coherently precipitates in $\mathrm{Ni}-\gamma$ matrix due to small lattice misfit strains [3], but no attempt has been made to control the morphology by misfit strains.

Recently, we examined the microstructure of Ni-25at $\% \mathrm{~V}$ quenched from high temperature $\mathrm{A} 1$ region [4, 5]. The high temperature $\mathrm{A} 1$ phase completely transforms to $\mathrm{D}_{22}$ phase during quench $\left(\mathrm{V}_{\mathrm{f}}=100 \%\right)$, and exhibits a fine coherent brick-like "multivariant structure (MVS)" consisting of three variants of $\mathrm{D}_{22}$ with $c$-axes perpendicular to each other. In the MVS, one of the three variants with quadrangular prism shape (major variant) of $90 \times 90 \times 150 \mathrm{~nm}$ has coherent interfaces of $(101)_{\mathrm{D} 022},(\overline{1} 01)_{\mathrm{D} 022}$ and $(010)_{\mathrm{D} 022}$, in fcc base index. The major variant particles are periodically arrayed with an interval of $30 \mathrm{~nm}$, and the remaining two channels parallel to $\{101)_{\mathrm{D} 022}$ and $\{010)_{\mathrm{D} 022}$ are filled with two other variants (minor variants) with their $c$-axes parallel to the $a$-axis of the major variant. The formation of MVS would be attributed to the minimization of the anisotropic strain fields due to the tetragonality against A1 matrix with the following lattice parameter relationship: $a_{\mathrm{D} 022}<a_{\mathrm{A} 1}<c_{\mathrm{D} 022} / 2$ [2, 3]. Since the morphology of MVS is just like $\gamma / \gamma^{\prime}$ two-phase morphology in superalloys, if rotated $45^{\circ}$ around [010] axis, it is attractive as high temperature material. However, this MVS is not stable at elevated temperatures, and drastically coarsens by coherency loss at interfaces $[5,6]$. The collapse of MVS is caused by a release from elastic constraint, accompanied by the increase in the lattice parameter ratio $c / a$ from nearly cubic value (2.006) to equilibrium value (2.04). Therefore, some modification to accommodate the elastic constraint is required to improve the thermal stability of MVS.

In this study, introduction of A1 phase into MVS has been attempted. First, we have focused on the hypo-stoichiometric composition of $\mathrm{Ni}_{3} \mathrm{~V}$ in the binary system, and identified the region to form MVS with A1 phase. Then, morphology control of the two-phase microstructure has been examined in terms of misfit strains through alloying.

\section{Experimental Procedures}

Four binary alloys with compositions of Ni-23V, Ni-20V, Ni-18V and Ni-17V (all compositions are given in atomic percent unless otherwise stated) were prepared in order to investigate the $\mathrm{A} 1 / \mathrm{D} 0_{22}$ two-phase microstructure. Ternary alloys containing Co, $\mathrm{Nb}$ or $\mathrm{Fe}$ were also prepared so as to change the misfit strains between $\mathrm{A} 1$ and $\mathrm{D}_{22}$ phases against Ni-20V. Note that $\mathrm{Co}$ and $\mathrm{Fe}$ preferentially substitute Ni-sublattice while $\mathrm{Nb}$ substitutes $\mathrm{V}$ sublattice in $\mathrm{Ni}_{3} \mathrm{~V}$ [7]. The five alloys of Ni-20V-10Co, Ni-15V- 
$5 \mathrm{Nb}, \mathrm{Ni}-19.5 \mathrm{~V}-2 \mathrm{Fe}, \mathrm{Ni}-19 \mathrm{~V}-4 \mathrm{Fe}$ and Ni-19V-6Fe, having 50 60 vol. $\%$ of $\mathrm{D}_{22}$ phase at $1073 \mathrm{~K}$, were selected based on the reported binary and ternary diagrams [1, 2, 8-13]. All of these alloys were prepared by arc melting in argon atmosphere with a non-consumable tungsten electrode as $35 \mathrm{~g}$ button ingots, using $3 \mathrm{~N} 7$ nickel pellets, $3 \mathrm{~N}$ vanadium tablets, $3 \mathrm{~N}$ cobalt lumps, $3 \mathrm{~N}$ niobium grains and electrolytic iron. Each button ingot was melted five times by turning over each time in order to avoid segregation. These ingots were cut to pieces with a size of $6.0 \times 6.0 \times 10.0 \mathrm{~mm}^{3}$ by an electro-discharged machine.

All samples were homogenized at 1573 or $1523 \mathrm{~K}$ (A1 single phase region) for $3.6 \sim 10.8 \mathrm{ks}$, followed by water quench. These treatments were conducted using a specially designed vertical furnace under argon atmosphere [14]. Aging treatments were employed in the $\mathrm{A} 1+\mathrm{D}_{22}$ two-phase region: $1273 \mathrm{~K}$ for $\mathrm{Ni}-23 \mathrm{~V}$ and $1073 \mathrm{~K}$ for binary $\mathrm{Ni}-(17-20) \mathrm{V}$ and ternary alloys. All samples for aging were sealed off in silica capsules under argon back-filled after evacuating to $8 \times 10^{-4} \mathrm{~Pa}$. After holding the capsules for $0.9 \sim 8640 \mathrm{ks}$ in the furnace, the samples were quenched into water quickly by breaking the capsules.

Microstructures were examined by transmission electron microscope (TEM). TEM discs with $0.15 \mathrm{~mm}$ in thickness and 3 $\mathrm{mm}$ in diameter were machined, then mechanically polished, followed by twin-jet electropolishing in a solution of ethanol with 12 vol. \% perchloric acid at $253 \mathrm{~K}$. The TEM observation was performed with an incident beam direction $\mathbf{B}=<100>$ so as to distinguish the three variants of $\mathrm{D}_{22}$. The planes and directions of $\mathrm{D}_{22}$ phase are indexed in the same way as A1 structure, although the unit cell of $\mathrm{DO}_{22}$ structure is twice of that of $\mathrm{A} 1$ along its $c$ axis. The misfit strains between $\mathrm{A} 1$ and $\mathrm{D}_{22}$ phases were calculated using selected area diffraction patterns obtained by means of microbeam method. The detail procedures will be described later.

\section{Results and Discussion}

\section{$\underline{\text { Formation of } \mathrm{A} 1 / \mathrm{D} 0_{22} \text { Two-phase Microstructure }}$}

Before investigating the morphology of two-phase microstructure, it is important to identify the region to form MVS in hypostoichiometric alloys. Figure 1 shows TEM dark field images (DFIs) of the binary alloys with $\mathrm{D}_{22}$ phase. The typical MVS in quenched $\mathrm{Ni}-25 \mathrm{~V}$ from $1573 \mathrm{~K}$ exhibits the major variant particles with square shape along $<101]_{\mathrm{D} 022}$ and the size of $90 \mathrm{~nm}$ [Fig. 1(a)] surrounded by channels of minor variants [Fig. 1(b)] with coherent interfaces. These images were taken with $\mathbf{B}=010$, and only two variants of $\mathrm{D}_{22}$ are visible, as schematically shown in Fig. 1(f). Similarly, the quenched Ni-23V completely transforms to $\mathrm{D}_{22}$ phase and exhibits MVS as seen in Fig. 1(c) where only major variant is excited. The major variant with a particle size of about $50 \mathrm{~nm}$ (indicated by a white dotted square) covers all over the sample with narrow channels of minor variants. In case of Ni-20V, MVS is obtained after short time aging at 1073 $\mathrm{K} / 0.9 \mathrm{ks}$, not in the quenched state where very fine $\mathrm{D}_{22}$ particles with $10 \mathrm{~nm}$ in size are distributed in A1 matrix. As shown in Fig. 1(d), the size of major variant particles in the MVS is about $20 \mathrm{~nm}$. Note that this sample is not completely $\mathrm{D}_{22}$ single phase and some channels are filled with disordered A1 phase, but the morphology is quite similar to MVS. In Ni-18V, no $\mathrm{D}_{22}$ can be recognized in the quenched state. After aging at $1073 \mathrm{~K} / 3.6 \mathrm{ks}$, it precipitates in A1 matrix as shown in Fig. 1(e), but the microstructure never becomes MVS even after further aging. In $\mathrm{Ni}-17 \mathrm{~V}$, only a small amount of $\mathrm{D}_{22}$ phase is recognized after long-term aging. Thus, MVS is formed in the hypo-stoichiometric binary alloys [Fig. 1(c, d)], but the formation becomes more difficult as V content decreases below 19 at $\%$.

The hypo-stoichiometric alloys showing MVS were further investigated. Figure 2 shows TEM images of Ni-23V and Ni-20V aged in $\mathrm{A} 1 / \mathrm{D0}_{22}$ two-phase region. After aging at $1273 \mathrm{~K}$ for 86.4 ks, Ni-23V exhibits coarse A1 phase with plate and particle shapes with the size of $100 \sim 500 \mathrm{~nm}$ in $\mathrm{D}_{22}$ matrix [Fig. 2(a)], and many dislocations are observed at the interfaces. On the other hand, Ni-20V aged at $1073 \mathrm{~K} / 864 \mathrm{ks}$ exhibits periodically aligned two-phase microstructure [Fig. 2(b)], where the bright and dark regions correspond to $\mathrm{D}_{22}$ and $\mathrm{A} 1$ phases, respectively. The shape of $\mathrm{D}_{22}$ phase is plate with about $130 \mathrm{~nm}$ in thickness, and A1 phase also has plate shape with about $70 \mathrm{~nm}$ in thickness. No dislocation is observed at the interfaces. In both cases, the selected area diffraction pattern (SADP) reveals the existence of only one variant of $\mathrm{D}_{22}$ phase, indicating that the major variant particles in MVS grow at the expense of minor variants and disordered A1 phase forms during aging. However, the formation mode of A1 phase is completely different; in $\mathrm{Ni}-23 \mathrm{~V}$, A1 phase precipitates incoherently at variant interfaces, whereas it forms coherently in $\mathrm{Ni}-20 \mathrm{~V}$. Figure 3 shows the change in volume fraction of $\mathrm{D}_{22}$ phase during the aging for the two alloys, together with those of other binary alloys. In $\mathrm{Ni}-23 \mathrm{~V}$, the volume fraction gradually decreases from 100 to $65 \%$ with aging. In contrast, the quenched $\mathrm{Ni}-20 \mathrm{~V}$ with a certain amount of A1 phase change to near single phase of $\mathrm{D}_{22}$ after short time aging $(0.9 \mathrm{ks})$, and then the fraction starts decreasing to $65 \%$ with aging. The interfaces in the twophase microstructure keep coherency even after prolonged aging, indicating that the A1 phase should be formed spinodally through continuous composition change. Unlike these two alloys, the volume fraction increases with aging in the alloys with $\mathrm{V}$ content less than 18 at $\%$.

From above results, there are three formation modes of $\mathrm{A} 1 / \mathrm{D}_{22}$ two-phase microstructure, depending on the alloy composition and heat treatment temperature:
1) $\mathrm{D}_{22} \rightarrow \mathrm{D}_{22}+\mathrm{A} 1$ (precipitation of $\mathrm{A} 1, \mathrm{Ni}-23 \mathrm{~V}$ )
2) $\mathrm{D}_{22} \rightarrow \mathrm{DO}_{22}+\mathrm{A} 1$ (phase separation, $\mathrm{Ni}-20 \mathrm{~V}$ )
3) $\mathrm{A} 1 \rightarrow \mathrm{D}_{22}+\mathrm{A} 1 \quad$ (precipitation of $\mathrm{DO}_{22}, \mathrm{Ni}-(17-18) \mathrm{V}$ )

The difference in the mode can be interpreted by the thermodynamic approach proposed by Soffa and Laughlin [15]. Figure 4 (a) shows a part of Ni-V binary diagram, showing the region where each mode occurs, together with the schematic Gibbs energy - composition curves of A1 $\left(\mathrm{G}_{\mathrm{A} 1}\right)$ and $\mathrm{D0}_{22}\left(\mathrm{G}_{\mathrm{D} 022}\right)$ phases at $1073 \mathrm{~K}$ [Fig. 4(b)]. Note that the phase boundaries of $\mathrm{A} 1 / \mathrm{A} 1+\mathrm{D}_{22}$ and $\mathrm{A} 1+\mathrm{D0}_{22} / \mathrm{DO}_{22}$ are coherent boundaries drawn based on the measured volume fraction, with an assumption that molar volume of $\mathrm{A} 1$ and $\mathrm{D}_{22}$ phases are nearly equal, and they are consistent with other reports $[8,9]$.

The region to form MVS in hypo-stoichiometric compositions can be specified below $\mathrm{T}_{0}$ temperature, as shown by hatching in Fig. 4(a). In this region, A1 phase becomes energetically unstable against $\mathrm{D}_{22}$ phase since $\mathrm{T}_{0}$ is a trace of composition where the Gibbs energy of $\mathrm{A} 1$ and $\mathrm{D}_{22}$ at given temperatures are equal. In quenching, the higher the $\mathrm{T}_{0}$, the easier the formation of MVS consisting of $\mathrm{DO}_{22}$ phase, because the driving force for the $\mathrm{A} 1 \rightarrow \mathrm{D}_{22}$ phase transformation becomes large enough. This is the case for the quenched $\mathrm{Ni}-23 \mathrm{~V}$. With decreasing $\mathrm{V}$ content, however, the formation of MVS becomes more difficult because of lower supersaturation of $\mathrm{V}$ as well as slow diffusion rate even though the driving force is still enough to form MVS. This is the case for the quenched $\mathrm{Ni}-20 \mathrm{~V}$. Thus, once the sample is heated again at temperatures just below $\mathrm{T}_{0}$, the ceased transformation 
could proceed again, resulting in MVS.

The different formation modes of the two-phase mixture (1) and (2) by aging can be explained by introducing the miscibility gap in $\mathrm{D}_{22}$ phase. Then, the region showing MVS in the two-phase region in Fig. 4(a) can be divided further into two regions $\mathbf{A}$ and $\mathbf{B}$ sectioned by $T_{S}$ line, where $T_{S}$ is an inflection point $(x)$ on the $G_{D 022}$ curve $\left(d^{2} G / d x^{2}=0\right)$ in Fig. $4(b)$. The region $\mathbf{A}$ is inside the $T_{S}$ point as well as the $T_{0}$ point, where the $G_{D 022}$ curve has a positive curvature $\left(\mathrm{d}^{2} \mathrm{G} / \mathrm{dx}^{2}>0\right)$, so that the $\mathrm{D} 0_{22}$ phase is energetically metastable against two-phase mixture as shown by the common tangent. This leads to a nucleation and growth of disordered A1 phase with a fixed composition marked by open circle on $G_{A 1}$ curve to reduce the chemical energy in the initial MVS state. The region $\mathbf{B}$, on the other hand, is inside the $T_{0}$ point but outside of the $T_{S}$ point, where the $G_{D 022}$ has a negative curvature $\left(\mathrm{d}^{2} \mathrm{G} / \mathrm{dx}^{2}<0\right)$, so that the thermodynamically unstable $\mathrm{D}_{22}$ phase continuously decomposes to V-lean and V-rich ordered phases first, followed by phase separation to the stable A1
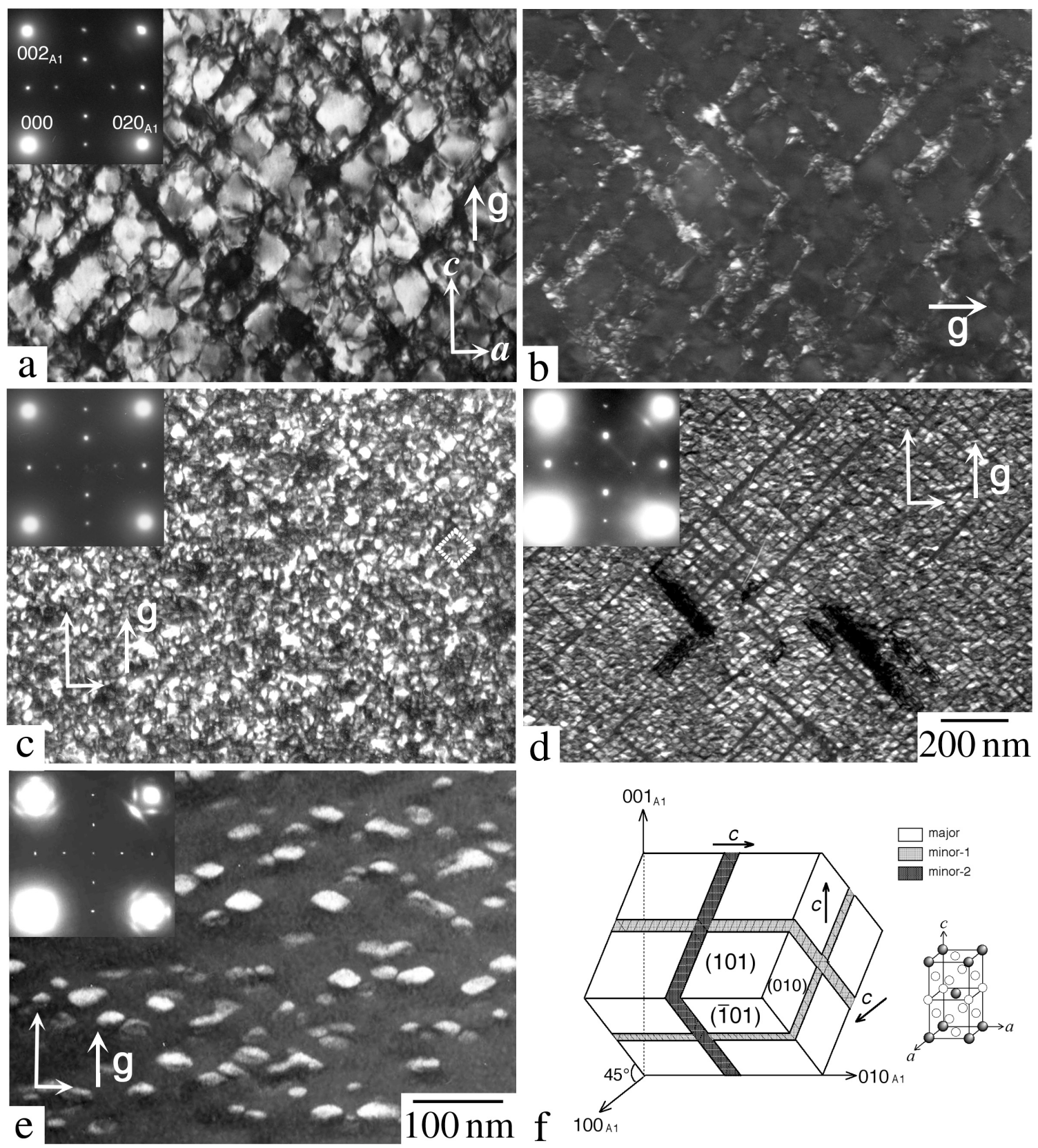

Figure 1. TEM DFIs of Ni-V binary alloys with $\mathrm{D}_{22}$ phase taken with $\mathbf{g}=002_{\mathrm{D} 022}\left(\mathbf{B}=010_{\mathrm{A} 1}\right):(\mathrm{a}, \mathrm{b})$ typical MVS in the quenched Ni-25V from $1573 \mathrm{~K}$ showing (a) major and (b) minor variants, (c) MVS in the quenched Ni-23V from 1573 $\mathrm{K}$ showing major variant, (d) MVS in Ni-20V obtained after aging at $1073 \mathrm{~K} / 0.9$ ks showing major variant, (e) $\mathrm{D} 0_{22}$ particles precipitated in Ni-18Vaged at $1073 \mathrm{~K} / 3.6 \mathrm{ks}$. (f) Schematic illustration of MVS, together with $\mathrm{D}_{22}$ structure. 

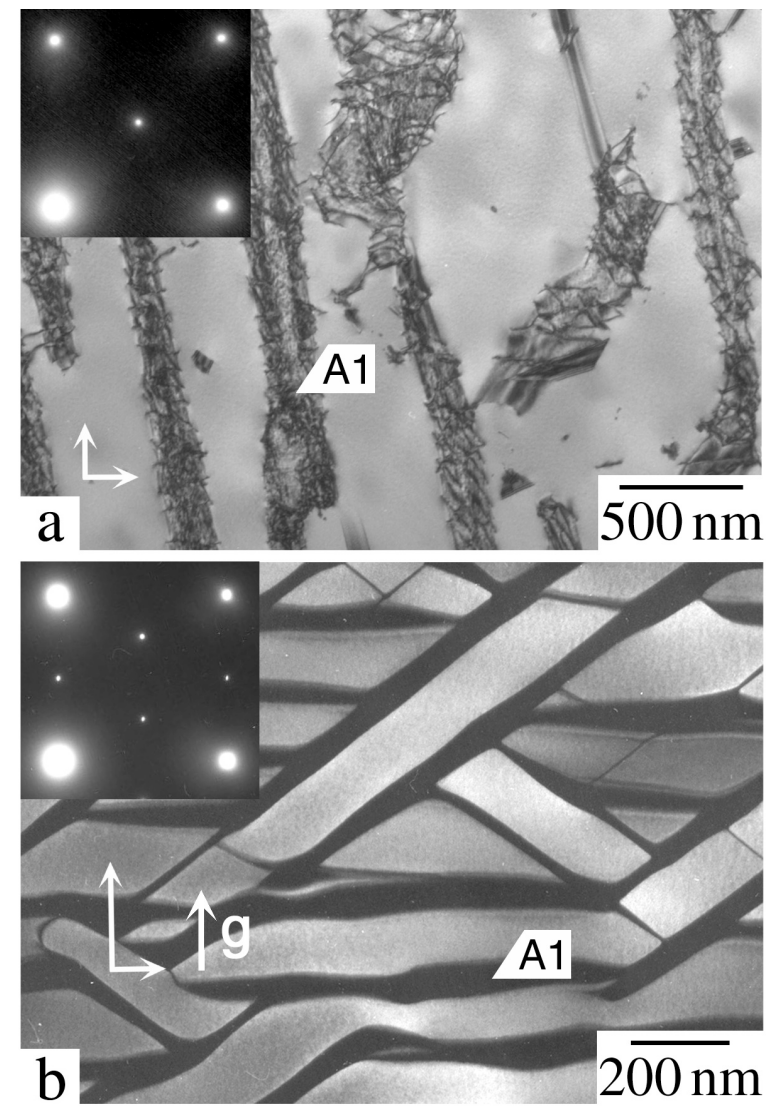

Figure 2. TEM images of the hypo-stoichiometric alloys showing different modes of two-phase microstructure formation $\left(\mathbf{B}=100_{\mathrm{A} 1}\right)$ : (a) $\mathrm{BFI}$ of $\mathrm{Ni}-23 \mathrm{~V}$ aged at $1273 \mathrm{~K}$ $186.4 \mathrm{ks}$, (b) DFI of Ni-20V aged at $1073 \mathrm{~K} / 864 \mathrm{ks}$, $\mathbf{g}=002_{\mathrm{D} 022}$.

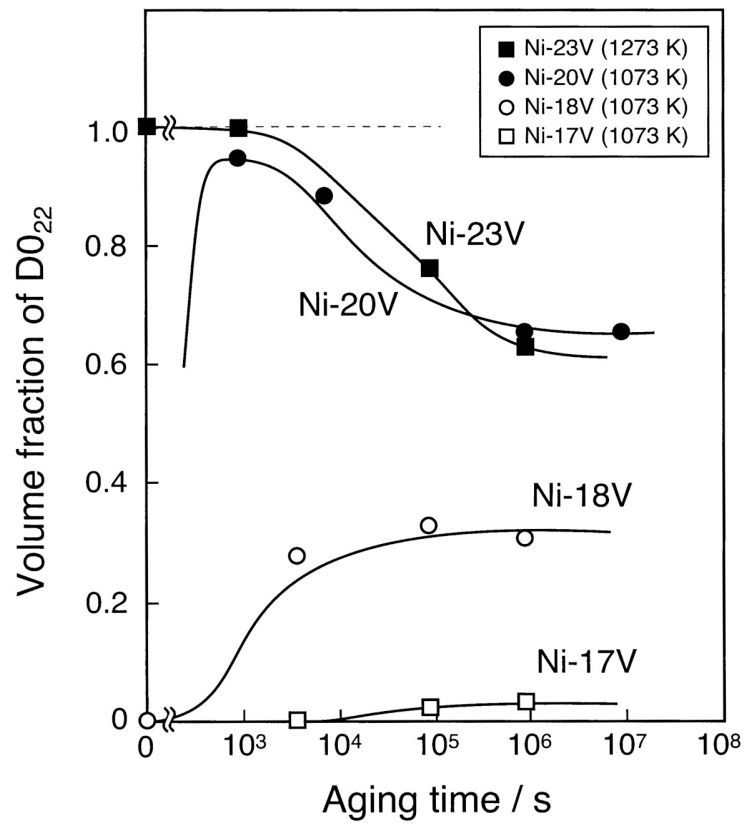

Figure 3. Change in volume fraction of $\mathrm{D}_{22}$ phase in Ni$\mathrm{V}$ binary alloys with aging in $\mathrm{A} 1 / \mathrm{D}_{22}$ two-phase region.

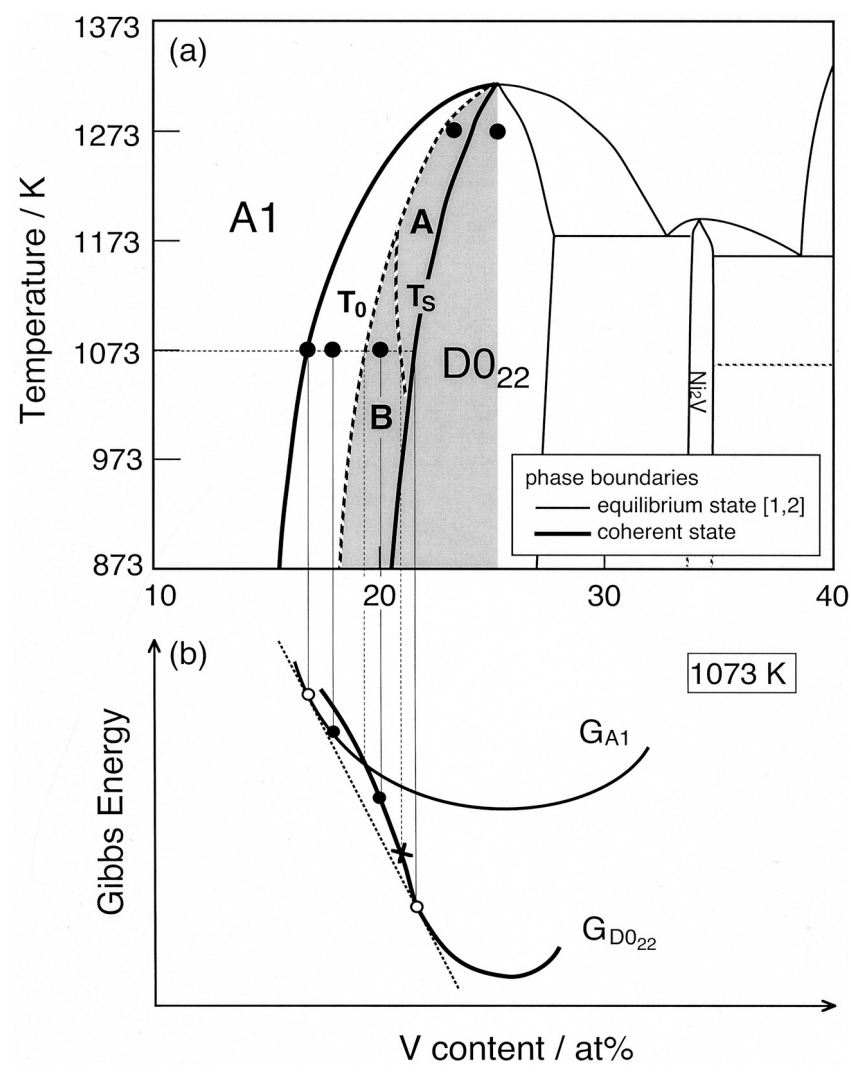

Figure 4. (a) Ni-V binary phase diagram showing the regions where different modes of two-phase microstructure formation take place. The thick lines are coherent phase boundaries. The hatched region is where MVS is formed. In the regions $\mathbf{A}$ and $\mathbf{B}$, precipitation of $\mathrm{A} 1$ within $\mathrm{D}_{22}$ and continuous phase separation of $\mathrm{D}_{22}$ take place, respectively. (b) The schematic Gibbs energy - composition curves for A1 $\left(\mathrm{G}_{\mathrm{A} 1}\right)$ and $\mathrm{D0}_{22}\left(\mathrm{G}_{\mathrm{D} 022}\right)$ phases at $1073 \mathrm{~K}$.

and $\mathrm{D}_{22}$ phases. The former is the case for $\mathrm{Ni}-23 \mathrm{~V}$ aged at 1273 $\mathrm{K}$ whereas the latter is for $\mathrm{Ni}-20 \mathrm{~V}$ aged at $1073 \mathrm{~K}$. The existence or absence of interfacial dislocations (Fig. 2) is one of the strong evidence to support these formation modes of $\mathrm{A} 1$ phase in $\mathrm{D}_{22}$ matrix. The other mode (3) in Ni-18V and $\mathrm{Ni}-17 \mathrm{~V}$ is, just like opposite case of mode (1), where the alloy compositions are initially outside of the $T_{0}$ point on the positive curvature of $G_{A 1}$, and the disordered single phase state is energetically unstable with respect to the stable two-phase mixture, resulting in precipitation of $\mathrm{D}_{22}$ phase in $\mathrm{Al}$ matrix.

\section{$\underline{\text { Morphology of Coherent A1/D0 } 22 \text { Two-phase Microstructure }}$}

The two-phase mixture in the region $\mathbf{B}$ is attractive because of the high volume fraction of $\mathrm{D}_{22}$ phase as well as the coherency of the interface even after long-term aging at elevated temperatures. However, the initial MVS is somehow coarsened, so that further improvement of thermal stability as well as morphology control of the two-phase microstructure are key issues for alloy development. In this section, we focus on the microstructure evolution of $\mathrm{Ni}$ $20 \mathrm{~V}$ formed in the region $\mathbf{B}$ and identify the fundamental factors governing the microstructure morphology in terms of the misfit 
strains between the two phases.

In the microstructure of Ni-20V [Fig. 2(b)], the diagonal plates of $\mathrm{D}_{22}$ phase are parallel to the edge-on planes close to $\{304)_{\mathrm{D} 022}$. Another plates along $\langle 100\rangle_{\mathrm{D} 022}$ were also confirmed to be parallel to $\{304)_{\mathrm{D} 022}$ which are not edge-on [5]. Since there are four crystallographically equivalent $\{304)_{\mathrm{D} 022}$ in the unit cell of $\mathrm{D}_{22}$, the morphology of this microstructure can be hereafter called as "maze".

The change in morphology from the initial MVS to maze microstructure is characterized by the following two points; (1) the change in shape of $\mathrm{D}_{22}$ from a quadrangular-prism into a plate by merging into each other, (2) the inclination of the habit plane from \{101) $)_{\mathrm{D} 022}$ to $\{304)_{\mathrm{D} 022}$. Figure 5 shows change in the $\mathrm{A} 1 / \mathrm{D} 0_{22}$ habit plane with aging. The habit plane is quantified as an angle $\theta$ between the edge-on habit plane and (001) $)_{\mathrm{D} 022}$. The angle is $45^{\circ}$ in MVS, and it gradually decreases to $35^{\circ}$. (1) and (2) take place simultaneously, but they are discussed separately in the following sections.

The A1/D0 ${ }_{22}$ Habit Plane. In order to identify the relationship between the habit plane and misfit strains, the lattice invariant theory [16] was applied to this study. Since the misfit strains between $\mathrm{A} 1$ and $\mathrm{D}_{22}$ phases are negative along $a$-axis $\left(\delta_{a}\right)$ and positive along $c$-axis $\left(\delta_{c}\right)$ in this system, formation of the irrational habit plane would be caused by the existence of an invariant line between the two phases. Figure 6(a) shows the schematic projection of lattices of $\mathrm{A} 1$ and $\mathrm{D}_{22}$ phases two-dimensionally depicted as a circle and an ellipse, respectively, on the coordinate of $[100]_{\mathrm{D} 022}$ and $[001]_{\mathrm{D} 022}$. The line connecting two intersection points is the invariant line. Based on the fact that all of the observed habit planes are parallel to one of the $a$-axes, the plane

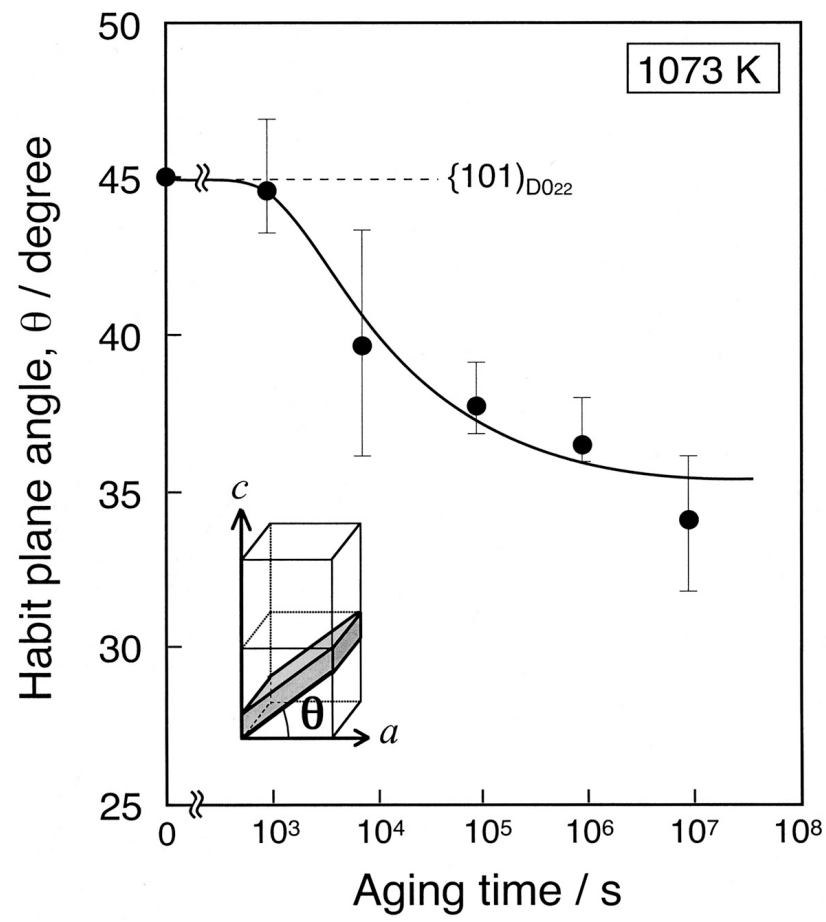

Figure 5. Change in the $\mathrm{A} 1 / \mathrm{D}_{22}$ habit plane angle of $\mathrm{Ni}-20 \mathrm{~V}$ with aging at $1073 \mathrm{~K}$. The habit plane is quantified as an angle $\theta$ between the edge-on habit plane and $(001)_{\mathrm{D} 022}$. consisting of an invariant line and an $a$-axis would be the habit. Therefore, two-dimensional treatment can be applied. The habit plane angle $\theta$ corresponds to the angle between the invariant line and $[100]_{\mathrm{D} 022} \quad\left(a\right.$-axis). Thus, the $\theta\left(=\tan ^{-1}(\mathrm{y} / \mathrm{x})\right)$ can be geometrically calculated using the following circle and ellipse equations;

$$
\begin{array}{ll}
\mathrm{x}^{2}+\mathrm{y}^{2}=1 & \text { (A1 lattice) } \\
\frac{\mathrm{x}^{2}}{\left(1+\delta_{a}\right)^{2}}+\frac{\mathrm{y}^{2}}{\left(1+\delta_{c}\right)^{2}}=1 & \left(\mathrm{D} 0_{22} \text { lattice }\right)
\end{array}
$$

where $\mathrm{x}$ and $\mathrm{y}$ are the coordinate of the intersection point. Then, the $\theta$ can be simply expressed as functions of the misfit strains;

$$
\theta=\tan ^{-1} \sqrt{\frac{-\left(1+2 \delta_{a}^{-1}\right)\left(\frac{\delta_{c}}{\delta_{a}}+\delta_{a}^{-1}\right)^{2}}{\frac{\delta_{c}}{\delta_{a}}\left(\frac{\delta_{c}}{\delta_{a}}+2 \delta_{a}^{-1}\right)\left(1+\delta_{a}^{-1}\right)^{2}}}
$$

This equation indicates that $\theta$ depends on both the misfit strain of $\delta_{a}$ and the ratio of misfit strains $\delta_{c} / \delta_{a}$. Figure 6(b) shows a plot of calculated $\theta$ as a function of misfit strain ratio using the above equation at two fixed values of $\delta_{a}$ : one (thick line) is the case of $\delta_{a}$ $=-0.003$, and the other (thin line) is $\delta_{a}=-0.030$. In both cases, the angle $\theta$ apparently approaches to $45^{\circ}$ as the misfit ratio approaches to -1 , and the deviation of $\theta$ between the two calculated lines is as much as $2^{\circ}$, even though the $\delta_{a}$ is changed by an order of magnitude. This result indicates that the habit plane strongly depends on the misfit strain ratio.

In order to verify the prediction, the misfit strains are measured in the sample of Ni-20V aged at $1073 \mathrm{~K} / 864 \mathrm{ks}$. Since all fundamental reflections of $\mathrm{D}_{22}$ structure coincide with those of A1 structure, it is impossible to measure misfit strains between these phases using conventional diffraction patterns. Then, microbeam method was applied in this study. The diameter of microbeam is small enough $(10 \sim 40 \mathrm{~nm})$ to obtain a diffraction pattern from each phase region. Figure 7 shows TEM DFI [Fig. 7(a)] and the microbeam diffraction patterns of A1 [Fig. 7(b)] and $\mathrm{D}_{22}$ [Fig. 7(c)] phases taken from the neighboring regions indicated by white circles in Fig. 7(a). Since the lattice parameters are inversely proportional to the distance of two reflections, $\delta_{a}$ and $\delta_{c}$ can be expressed as follows, using $r_{\mathrm{Al}}, r_{a}$ and $r_{c}$, which are indicated in Fig. 7(b, c):

$$
\begin{aligned}
& \delta_{a}=\frac{a_{D 022}-a_{A I}}{a_{A I}}=\left(r_{A I} / r_{a}\right)-1 \\
& \delta_{c}=\frac{c_{D 022} / 2-a_{A I}}{a_{A I}}=\left(r_{A I} / r_{c}\right)-1
\end{aligned}
$$

The obtained misfit strains are shown in Table I, together with the observed and calculated angles of habit plane. The values of $\delta_{a}$ and $\delta_{c}$ are about -0.003 and +0.006 , respectively, and the misfit strain ratio is about -2 . Then, $\theta$ is calculated as $34.5^{\circ}$. This value agrees well with the observed value of $36.5^{\circ}$. Thus, the inclination of habit plane with aging is associated with the continuous change in misfit strains due to the phase separation.

The Shape of $\mathrm{D}_{22}$ Phase. The change in the shape of $\mathrm{D}_{22}$ phase during aging is related to the growth directions of initial particle. The growth along two directions, an $a$-axis and the invariant line, 
(a)
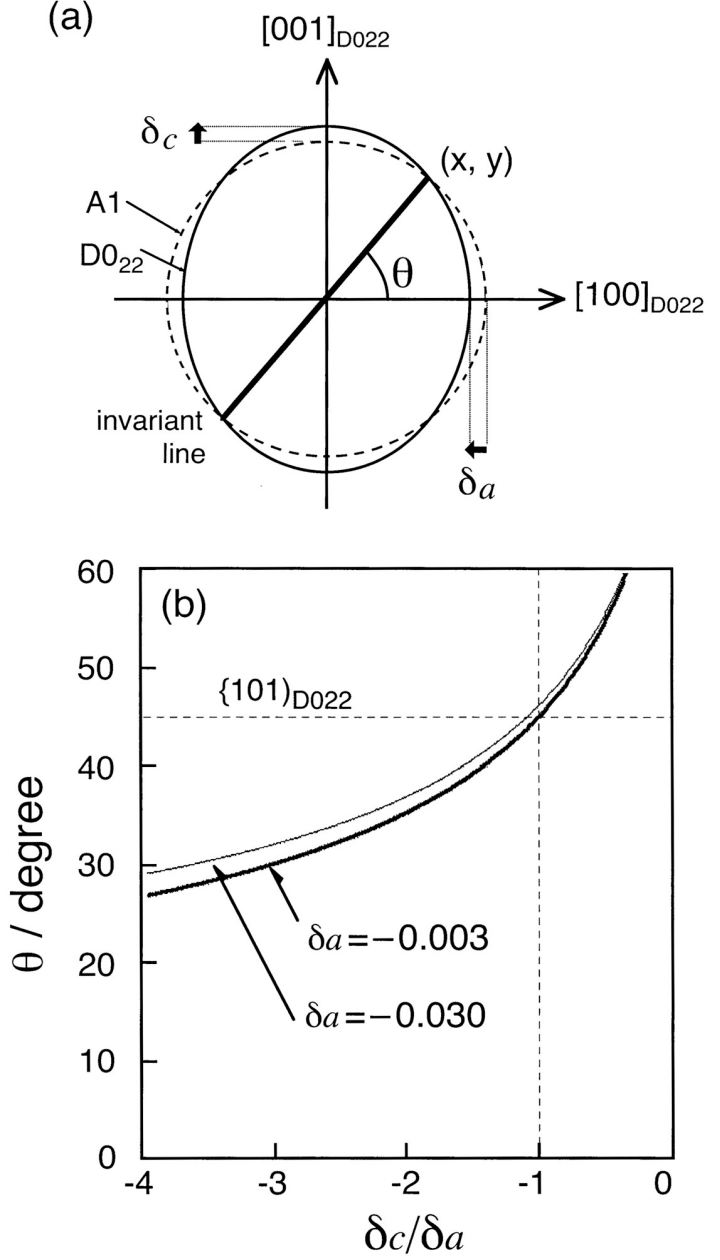

Figure 6. Relationship between the $\mathrm{A} 1 / \mathrm{D}_{22}$ habit plane and misfit strains: (a) the schematic projection of lattices of A1 and $\mathrm{D}_{22}$ phases depicted as a circle and an ellipse on the coordinate of [100] and [001], showing the existence of an invariant line in case of $\delta_{a}<0<\delta_{c}$, (b) calculated angle of invariant line as a function of misfit strain ratio $\delta_{c} / \delta_{a}$ with fixed $\delta_{a}$ of -0.003 (thick line) and -0.030 (thin line).

is necessary to form plate shape observed in $\mathrm{Ni}-20 \mathrm{~V}$. In other words, the plate shape is the case that the growth rate along $a$-axis $\left(v_{a}\right)$ and the invariant line $\left(v_{i}\right)$ are on the same level. Based on the fact that the direction with smaller misfit becomes preferred direction to grow, as is clear in case of $\mathrm{Ni}_{3} \mathrm{Nb}-\delta$ phase [17], $v_{a}$ depends on the value of $\left|\delta_{a}\right|$. Thus, the value of $\left|\delta_{a}\right|$ should be the key factor for the shape of $\mathrm{D}_{22}$. Based on this prediction, reduction in $\left|\delta_{a}\right|$ would be effective in improving the coarsened morphology of $\mathrm{D}_{22}$ by suppressing the growth along the invariant line, since $v_{a}$ becomes larger than $v_{i}\left(v_{a}>v_{i}\right)$.

\section{$\underline{\text { Microstructure Control of A1/D0 } 22 \text { Two-phase Alloys }}$}

In the previous section, $\delta_{c} / \delta_{a}$ and $\left|\delta_{a}\right|$ are found to be the key factors for the habit plane and the shape of $\mathrm{D}_{22}$, respectively.
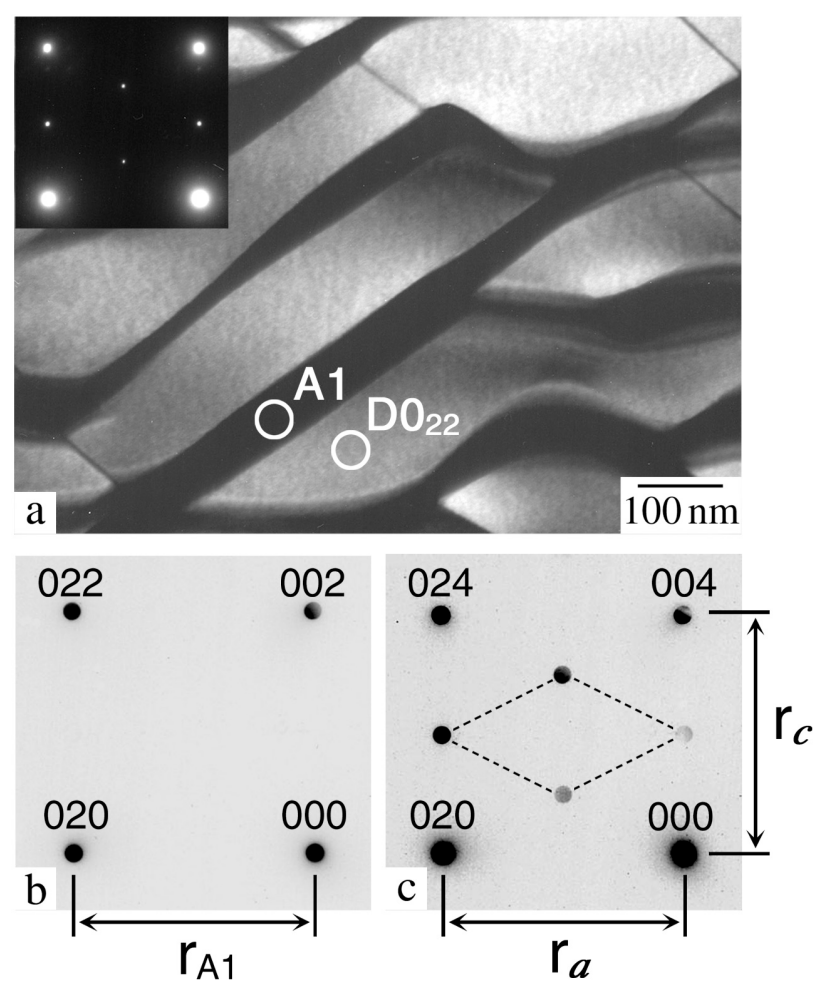

Figure 7. Measurement of misfit strains, $\delta_{a}$ and $\delta_{c}$, using microbeam diffraction method: (a) TEM DFI and SADP of $\mathrm{Ni}-20 \mathrm{~V}$ aged at $1073 \mathrm{~K} / 864 \mathrm{ks}(\mathbf{B}=100),(\mathrm{b}, \mathrm{c})$ microbeam diffraction patterns of $\mathrm{A} 1$ and $\mathrm{D}_{22}$ obtained from the regions marked with white circles in (a).

Table I. Measured misfit strains between A1 and D0 22 phases in Ni-20V aged at $1073 \mathrm{~K} / 864 \mathrm{ks}$, together with observed and calculated angles of habit plane

\begin{tabular}{cccc}
\hline \multicolumn{2}{c}{ Lattice misfit strain } & $\begin{array}{c}\theta / \text { degree } \\
\text { (observed) }\end{array}$ & $\begin{array}{c}\theta / \text { degree } \\
\text { (calculated) }\end{array}$ \\
\hline$\delta_{a}$ & $\delta_{c}$ & 36.5 & 34.5 \\
\hline-0.0027 & 0.0058 & & \\
\hline
\end{tabular}

Based on the findings, an attempt has been made to control the two-phase microstructure by changing the misfit strains through alloying.

Table II shows effect of third element addition to $\mathrm{Ni}-25 \mathrm{~V}$ on the lattice parameters of $\mathrm{A} 1$ and $\mathrm{D}_{22}$ phases in alloys which become single phase of $\mathrm{A} 1$ and $\mathrm{D}_{22}$ at $1473 \mathrm{~K}$ and $1273 \mathrm{~K}$, respectively [7]. From these lattice parameters, misfit strains between the two phases can be calculated. In the stoichiometric Ni-25V, $\delta_{a}$ and $\delta_{c}$ are -0.0054 and +0.0130 , respectively. Additions of Co ( $\mathrm{Ni}$ site) and $\mathrm{Nb}$ (V site) decrease $\left|\delta_{a}\right|$, and the effect of $\mathrm{Nb}$ is more obvious than that of Co. However, $\delta_{c}$ decreases by Co addition, whereas it increases by $\mathrm{Nb}$ addition. On the other hand, addition of $\mathrm{Fe}$ to $\mathrm{Ni}$ site increases $\left|\delta_{a}\right|$, while $\delta_{c}$ remains almost unchanged. Although these misfit strains cannot be directly applied to the microstructure consisting of two phases with different 
compositions, these trends can be referred for predicting the effects of the third element on the $\mathrm{A} 1 / \mathrm{D}_{22}$ two-phase microstructure. In the early stage of continuous phase separation $\left(\mathrm{D}_{22} \rightarrow \mathrm{D} 0_{22}+\mathrm{A} 1\right)$, these trends would be helpful, since the compositions of the two phases are very close to each other. However, after prolonged aging, partition coefficients of $\mathrm{Ni}$ and $\mathrm{M}$ between the two phases have to be taken into consideration, since the lattice parameters also depend on Ni content $[2,3]$.

According to Table II, it is expected that addition of $\mathrm{Co}$ and $\mathrm{Nb}$ are effective in suppressing the coarsening of $\mathrm{D}_{22}$ along the invariant line. On the other hand, $\mathrm{Fe}$ addition is expected to maintain the shape unchanged.

Figure 8 shows TEM images of two-phase microstructure in ternary alloys aged at $1073 \mathrm{~K}$ for $864 \mathrm{ks}$. In the alloy with $10 \%$
Co [Fig. 8(a)], the microstructure observed from $\mathbf{B}=010_{\mathrm{A} 1}$ consists of two variants of $\mathrm{D}_{22}$ (dark) with parallelogram shape and $\mathrm{A} 1$ phase (bright) with rhombic shape aligned alternately, exhibiting so-called "chessboard" microstructure. Since all of the observed habit planes in this figure are edge-on, the morphology of both phases are prism shape elongated along $a$-axis. The habit plane is close to \{304) $)_{\mathrm{D} 022}$. In case of $5 \% \mathrm{Nb}$ addition, however, "chessboard-like" microstructure is obtained as shown in Fig. 8(b). The morphology of $\mathrm{D}_{22}$ phase is recognized to be prism elongated along $a$-axis, but unlike the Co added alloy, the cross sectional shape is somehow irregular parallelogram and the habit plane is much closer to $(001)_{\mathrm{D} 022}$. In contrast, Fe added alloys remain the "maze" microstructure [Fig. 8(c)], regardless of $\mathrm{Fe}$ content [5].

Table II. Effect of third element M (M: Co, Nb, Fe) addition to Ni-25V on the lattice parameters of A1 and $\mathrm{D} 0_{22}$ phases and misfit strains between the two phases with the same composition

\begin{tabular}{|c|c|c|c|c|c|}
\hline \multirow{3}{*}{ Alloy composition / at $\%$} & \multicolumn{3}{|c|}{ Lattice Parameter $/ \AA$} & \multirow{2}{*}{\multicolumn{2}{|c|}{ Misfit strain }} \\
\hline & \multirow{2}{*}{$\begin{array}{c}\mathrm{A} 1^{1)} \\
a\end{array}$} & \multicolumn{2}{|c|}{$\mathrm{D}_{22}^{2)}$} & & \\
\hline & & $a$ & $c / 2$ & $\delta_{a}$ & $\delta_{c}$ \\
\hline $\mathrm{Ni}-25 \mathrm{~V}$ & 3.562 & 3.543 & 3.608 & -0.0054 & 0.0130 \\
\hline $\mathrm{Ni}-25 \mathrm{~V}-7 \mathrm{Co}$ & 3.564 & 3.549 & 3.604 & -0.0042 & 0.0111 \\
\hline $\mathrm{Ni}-23 \mathrm{~V}-2 \mathrm{Nb}$ & 3.567 & 3.554 & 3.618 & -0.0038 & 0.0141 \\
\hline $\mathrm{Ni}-25 \mathrm{~V}-3 \mathrm{Fe}$ & 3.564 & 3.544 & 3.611 & -0.0058 & 0.0129 \\
\hline
\end{tabular}

${ }^{1)}$ Water quenched from $1473 \mathrm{~K},{ }^{2)}$ Water quenched from $1273 \mathrm{~K}$
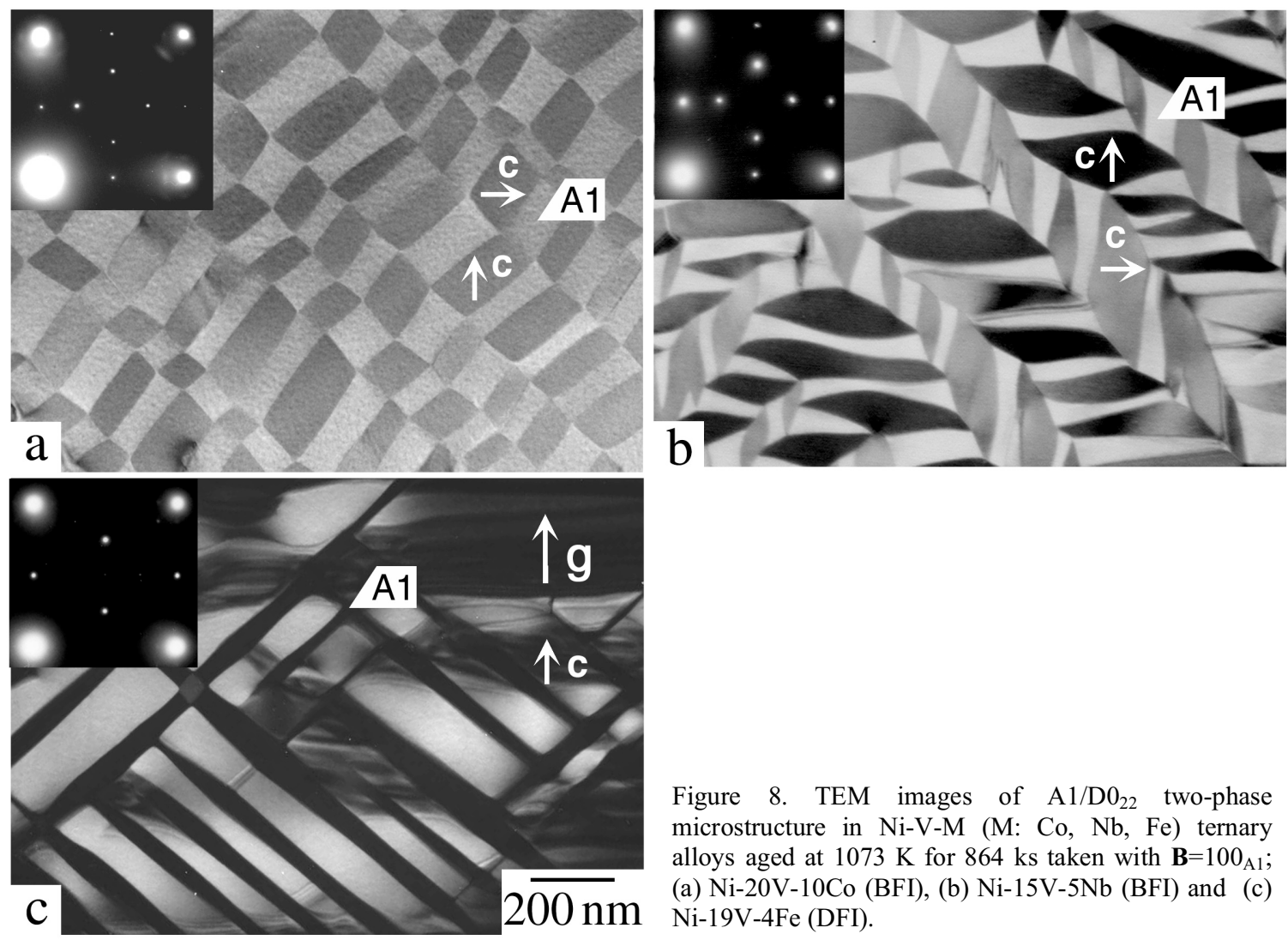

Figure 8. TEM images of $\mathrm{A} 1 / \mathrm{D}_{22}$ two-phase microstructure in Ni-V-M (M: Co, Nb, Fe) ternary alloys aged at $1073 \mathrm{~K}$ for 864 ks taken with $\mathbf{B}=100_{\mathrm{A} 1}$; (a) Ni-20V-10Co (BFI), (b) Ni-15V-5Nb (BFI) and (c) Ni-19V-4Fe (DFI). 
Table III. Misfit strains measured by microbeam method in the binary and the ternary alloys with $\mathrm{Co}, \mathrm{Fe}$ and $\mathrm{Nb}$ aged

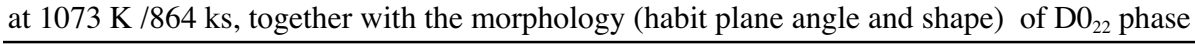

\begin{tabular}{|c|c|c|c|c|c|}
\hline \multirow{2}{*}{ Alloy composition / at $\%$} & \multicolumn{3}{|c|}{ Lattice misfit strain } & \multirow{2}{*}{$\begin{array}{l}\theta / \text { degree } \\
\text { (observed) }\end{array}$} & \multirow{2}{*}{ Shape of $\mathrm{DO}_{22}$} \\
\hline & $\delta_{a}$ & $\delta_{c}$ & $\delta_{c} / \delta_{a}$ & & \\
\hline $\mathrm{Ni}-20 \mathrm{~V}$ & -0.0027 & 0.0058 & -2.14 & 36.5 & plate \\
\hline $\mathrm{Ni}-20 \mathrm{~V}-10 \mathrm{Co}$ & -0.0020 & 0.0039 & -1.97 & 37.7 & prism \\
\hline $\mathrm{Ni}-15 \mathrm{~V}-5 \mathrm{Nb}$ & -0.0015 & 0.0110 & -7.36 & - & prism \\
\hline $\mathrm{Ni}-19.5 \mathrm{~V}-2 \mathrm{Fe}$ & -0.0031 & 0.0069 & -2.20 & 38.8 & \\
\hline $\mathrm{Ni}-19 \mathrm{~V}-4 \mathrm{Fe}$ & -0.0060 & 0.0077 & -1.29 & 40.5 & plate \\
\hline $\mathrm{Ni}-19 \mathrm{~V}-6 \mathrm{Fe}$ & -0.0061 & 0.0067 & -1.10 & 43.6 & \\
\hline
\end{tabular}

Table III shows measured misfit strains, together with observed habit plane angle and the shape of $\mathrm{D}_{22}$. In all alloys, $\delta_{a}$ and $\delta_{c}$ are negative and positive, respectively, and $\left|\delta_{c}\right|$ is larger than $\left|\delta_{a}\right|$. By comparing the value of $\delta_{a}$, it is clear that the shape of $\mathrm{D}_{22}$ phase is plate in alloys with $\left|\delta_{a}\right| \geq 0.0027$ (Ni-20V and $\mathrm{Fe}$ added alloys) and prism in alloys with $\left|\delta_{a}\right| \leq 0.0020$ (Co and $\mathrm{Nb}$ added alloys). This result agrees well with the prediction, and there is no dependency on $\delta_{c}$, although $\delta_{c}$ is small in Co added alloy $(+0.0039)$ while it is much larger in $\mathrm{Nb}$ added alloy $(+0.011)$. Thus, the value of $\delta_{a}$ is a key factor for control of the morphology, and the threshold exists at around $\left|\delta_{a}\right|=0.002$.

Figure 9 shows change in the habit plane angle [Fig. 9(a)] and misfit strain ratio [Fig. 9(b)] as a function of $\mathrm{M}$ content (M: Co, $\mathrm{Fe})$. In $\mathrm{Ni}-20 \mathrm{~V}$, the value of $\theta$ is $36.5^{\circ}$. Addition of Co has little effect on the change in the habit plane and the angle $\theta$ is $37.7^{\circ}$ even by $10 \%$ addition. On the other hand, the angle $\theta$ is sensitive to Fe content. It increases linearly toward $45^{\circ}$, which is $\{110)_{\mathrm{D} 022}$ habit plane, with increase in Fe content. In the mean time, misfit strain ratio increases from -2 to -1 by $\mathrm{Fe}$ addition, although it remains almost unchanged by Co addition. Thus, it is clear that the habit plane can be controlled by misfit ratio and becomes $\{101)_{\mathrm{D} 022}$ when the ratio becomes -1 , as predicted in Fig. 6 . This is also consistent with the result of $\mathrm{Nb}$ added alloy, which exhibits the habit planes much closer to $(001)_{\mathrm{D} 022}$ and has large misfit strain ratio of -7 .

All of these above results are the cases that the invariant line exists between the two phases due to $\delta_{a}<0<\delta_{c}$. Figure 10 shows whole picture of the morphology map of $\mathrm{D}_{22}$ phase as functions of $\delta_{a}$ and $\delta_{c}$, together with the plots obtained in this study. In the region of $\delta_{a}<0<\delta_{c}$ and $\left|\delta_{a}\right|<\left|\delta_{c}\right|$, it is clear that the value of $\delta_{a}$ is a factor determining the microstructure morphology, either maze or chessboard microstructure, regardless of $\delta_{c}$. On the other hand, in the region without invariant line, the relative relationship between the misfit strains, $\delta_{a}<\delta_{c}$ or $\delta_{a}>\delta_{c}$, is important, because the morphology of $\mathrm{D}_{22}$ phase becomes elongated along directions with minimum misfit strain. For example, the morphology of $\mathrm{Ni}_{3} \mathrm{Nb}-\gamma^{\prime \prime}$ phase, which is a metastable $\mathrm{D}_{22}$ phase in wrought Nibase superalloys such as Inconel 718, is disc shape with habit plane of $(001)_{\mathrm{D} 022}$, since $\delta_{a}$ and $\delta_{c}$ are +0.009 and +0.037 , respectively [18]. In the case of $\delta_{a}>\delta_{c}>0$, the morphology should become a rod shape elongated along $c$-axis. In addition, in the case of metastable $(\mathrm{Cu}, \mathrm{Ni})_{3} \mathrm{Sn}$ phase, the misfit strains $\delta_{a}$ and $\delta_{c}$ were reported to be +0.038 and -0.003 , respectively [19]. These values imply the existence of invariant line, but observed morphology is rod shape elongated along $c$-axis. This is reasonable because of $\left|\delta_{a}\right|>>\left|\delta_{c}\right|$, so that the $\theta$ becomes close to $90^{\circ}$, leading to the preferred growth along the $c$-axis.

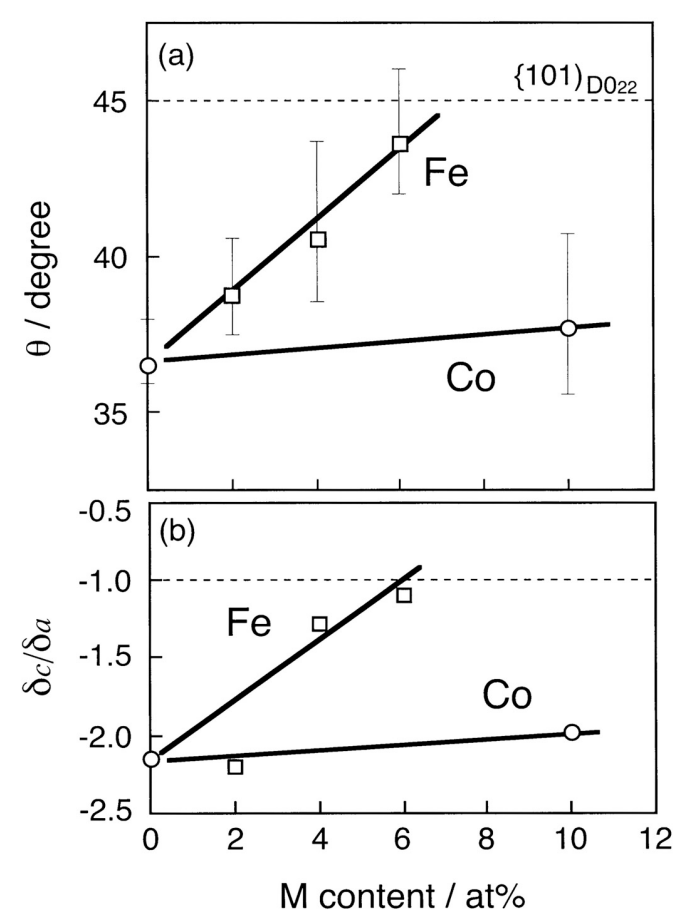

Figure 9. Change in the habit plane angle (a) and misfit strain ratio (b) with $\mathrm{M}$ content $(\mathrm{M}$ : $\mathrm{Co}, \mathrm{Fe})$ in ternary alloys aged at $1073 \mathrm{~K} / 864 \mathrm{ks}$.

Finally, from the viewpoint of thermal stability of MVS, chessboard microstructure is the most attractive, since the coarsening of $\mathrm{D}_{22}$ phase takes place only along an $a$-axis. Thus, control of misfit strains to be $\left|\delta_{a}\right|<0.002$ and $\delta_{c} / \delta_{a} \approx-1$ is effective in preventing drastic morphology change of $\mathrm{D}_{22}$ phase at elevated temperatures.

\section{Conclusion}

1) In the hypo-stoichiometric composition, MVS of $\mathrm{D}_{22}$ phase is formed below $\mathrm{T}_{0}$ temperature. By aging in the $\mathrm{A} 1 / \mathrm{D} 0_{22}$ two-phase 


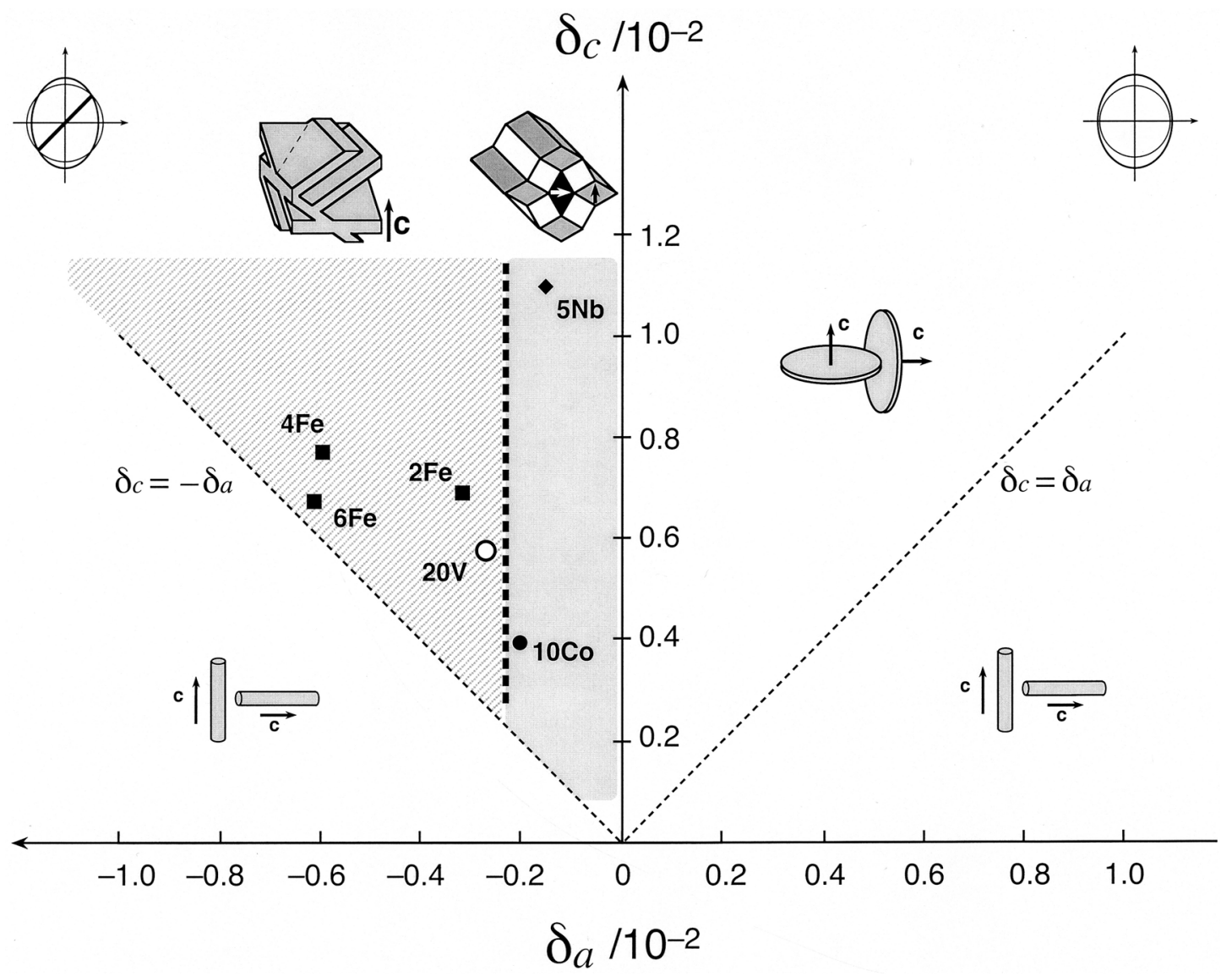

Figure 10. Morphology map of coherent $\mathrm{D}_{22}$ phase in $\mathrm{A} 1$ matrix plotted as functions of misfit strains. The investigated alloys in this study ranges in the hatched region $\left(\delta_{a}<0<\delta_{c},\left|\delta_{a}\right|<\left|\delta_{c}\right|\right)$. $\delta_{a}=-0.002$ is the threshold value for microstructure morphology, maze or chessboard. In the region without invariant line, the $\mathrm{D}_{22}$ has a shape elongated along the direction with less misfit strain.

region, A1 phase is introduced into MVS by two different modes; precipitation with incoherent interfaces (above $\mathrm{T}_{\mathrm{S}}$ ) and continuous phase separation (below $\mathrm{T}_{\mathrm{S}}$ ). The latter case is attractive because interface between the two phases remains coherency after longterm aging.

2) In the coherent $\mathrm{A} 1 / \mathrm{D}_{22}$ two-phase microstructure, the plane parallel to an $a$-axis of $\mathrm{D}_{22}$ and the invariant line between the two phases becomes the habit. The shape of $\mathrm{D}_{22}$ phase becomes either plate or prism, depending on the relative growth rate along an $a$-axis and the invariant line.

3) Control of the morphology of $\mathrm{D}_{22}$ phase is possible by changing misfit strains $\left(\delta_{a}<0<\delta_{c}\right)$. The misfit strain ratio $\delta_{c} / \delta_{a}$ is the dominant factor to determine the habit plane, and the habit plane becomes $\{101)_{\mathrm{D} 022}$ when the ratio becomes close to -1 . On the other hand, the value of $\left|\delta_{a}\right|$ can change the shape of $\mathrm{D}_{22}$ phase from plate to prism when $\left|\delta_{a}\right|$ becomes smaller than 0.002 , leading to the change in the microstructure morphology from maze to chessboard.

\section{Acknowledgement}

This research was partially supported by the grant-in-aid (13011570) for JSPS Fellows and in part by grant-in-aid (14205102) for Scientific Research from Ministry of Education, Culture, Sports, Science and Technology.

\section{References}

1. J.F. Smith, and O.N. Carlson, "The Ni-V (Nickel-Vanadium) System," Bull Alloy Phase Diagrams, 3 (1982), 342-348.

2. W.B. Pearson, and W.J. Hume-Rothery, "The Constitution and Structure of Nickel-Vanadium Alloys in the Region 0-60 At.-\% Vanadium," J Inst Metals, 80 (1952), 641-652.

3. K-M. Chang, "On the Habit Plane of $\gamma "-\mathrm{Ni}_{3} \mathrm{~V}$ Precipitates," Acta Metall, 30 (1982), 961-964. 
4. A. Suzuki, M. Takeyama, and T. Matsuo, "A $1 \rightarrow \mathrm{D}_{22}$ transformation and multi-variant structure of $\mathrm{Ni}_{3} \mathrm{~V}, "$ Defect Properties and Related Phenomena in Intermetallic Alloys, ed. E.P. George, H. Inui, M.J. Mills, and G. Eggeler, (Warrendale, PA: Materials Research Society, 2003), 753, 363-368.

5. A. Suzuki, "Microstructure Evolution and Morphology of $\mathrm{D}_{22}$ Compound in Ni Base Alloys," (Ph.D. thesis, Tokyo Institute of Technology, 2003).

6. A. Suzuki, H. Kojima, T. Matsuo, and M. Takeyama, "Alloying effect on stability of multi-variant structure of $\mathrm{Ni}_{3} \mathrm{~V}$ at elevated temperatures," Intermetallics, 12 (2004), to be published.

7. M. Okihashi, "Alloying effect on the crystal structure of $\mathrm{Ni}_{3} \mathrm{~V}$ $\gamma$ "," (Master thesis, Tokyo Institute of Technology, 2002).

8. H.A. Moreen, R. Taggart, and D.H. Polonis, "The Formation of Modulated Structures in Ni-V Alloys," Metall Trans, 5 (1974), 79-90.

9. S. Kobayashi, T. Sumi, T. Koyama, and T. Miyazaki, "Determination of coherent phase boundaries in $\mathrm{Ni}-\mathrm{V}$ and $\mathrm{Ni}-\mathrm{Mo}$ alloys by utilizing macroscopic composition gradient," J Japan Inst Metals, 60 (1996), 22-28.

10. K.P. Gupta, S.K. Mukherjee, A.K. Jena, and S.B. Rajendraprasad, "The Cobalt-Nickel-Vanadium System," J Alloy Phase Diagrams, 3 (1987), 105-115.

11. R. Nino, T. Mohri, Y. Terada, C-S. Oh, and T. Suzuki, "Phase diagram of $\mathrm{Ni}_{3} \mathrm{~V}-\mathrm{Co}_{3} \mathrm{~V}$ pseudobinary system," J Phase Equilibria, 20 (1999), 29-34.

12. G.V. Raynor, and V.G. Rivlin, "Phase Equilibria in Iron Ternary Alloys. X. -Critical Evaluation of Constitution of CobaltIron-Vanadium System," Int Met Rev, 28 (1983), 211-227.

13. T. Ueyama, M.M. Ghanem, N. Miura, M. Takeyama, and T. Matsuo, "Phase stability of $\mathrm{Ni}_{3} \mathrm{Nb}-\delta$ phase in $\mathrm{Ni}-\mathrm{Nb}-\mathrm{M}$ systems at elevated temperatures," THERMEC' 97 , ed. T. Chandra and T. Sakai (Warrendale, PA: TMS/AIME, 1997), 1753-1760.

14. A. Suzuki, M. Takeyama, and T. Matsuo, "Transmission electron microscopy on the phase equilibria among $\beta, \alpha$ and $\alpha_{2}$ phases in Ti-Al binary system," Intermetallics, 10 (2002), 915924.

15. W.A. Soffa, and D.E. Laughlin, "Decomposition and Ordering Process Involving Thermodynamically First-Order Order $\rightarrow$ Disorder Transformations," Acta Metall, 11 (1989), 3019-3028.

16. U. Dahmen, "Orientation Relationship in Precipitation Systems," Acta Metall, 30 (1982), 63-73.

17. M. Takeyama, H. Yokota, M.M. Ghanem, and T. Matsuo, "Phase Equilibria and Microstructure Control Using $\mathrm{Ni}_{3} \mathrm{Nb}-\delta$ Phase in Ni-Nb-Fe Ternary System at Elevated Temperatures," Special Issue: J Materials Processing Technology, Ed. T. Chandra, K. Higashi, C. Suryanarayana, and C. Tome (Elsevier Science, UK, 2001), 117-3, Section D7 [CD-ROM].
18. J.M. Oblack, D.H. Paulonis, and D.S. Duvall, "Coherency Strengthening in Ni-Base Alloys Hardened by $\mathrm{DO}_{22}-\gamma^{\prime \prime}$ Precipitates," Metall Trans, 5 (1974), 143-153.

19. J-C. Zhao, and M.R. Notis, "Spinodal decomposition, ordering transformation, and discontinuous precipitation in a $\mathrm{Cu}-15 \mathrm{Ni}-$ 85Sn alloy," Acta Materialia, 46 (1998), 4203-4218. 